\section{My Future is Not Mine}

\section{Cassandra Sukraj}

My name is Cassandra Sukraj and I'm 18 years old from Toronto. I am currently a first-year postsecondary student, slowly building my artistic career alongside my academics. This includes focusing on my passion for poetry as well as graphic design. My piece in this journal, My Future is not Mine, expresses the way I envision my future I pretty much don't. I feel that it is mostly unpredictable and essentially none of my business. Of course I still plan and create goals for the future, however I understand that they are always subject to change and I tend to leave nearly everything for 'future Cassandra.' I've learned to trust and reassure myself that things will always work out, and therefore I simply envision my future as whatever I will want it to be when the time comes. My values and dreams continue to change as I grow and mature, so although I cannot paint a picture of the future as of yet, I know it will be exactly what I want it to be.
Keywords

future, poetry, depression, change, trust 


\section{Abstract}

This piece is a homage to my struggles in imagining a future for myself. It follows the process that I often experience going from seeing no future for myself, to concluding that my future is essentially none of my business. It looks at the hopelessness that can be felt when picturing a future while in the depths of depression and clings to the hope that things wouldn't always be this way, and that it will be figured out in time. As humans we are ever-growing, and this piece recognizes that and applies this notion to trust in the future self. A self-formulated quote that I often keep in mind is "You are not your thoughts or your mind, you are an entity much greater than that. You are an observer of the mind." Remembering this helps me write my poetry as I can separate myself from my thoughts and emotions, and write as an observer. 
My future is out of reach,

It's like climbing a rope, but my arms are giving up on me.

Do I even deserve it?

With the sins, I have committed and the hurt that I

have caused - are there futures for people like me?

Maybe I'm wallowing in self-pity

Maybe I'm aware this world's future will have nothing left for me

Maybe I'm forever trapped by the trauma and pain that my past has left for me

This is not life

But rather being alive

Why formulate a future when the only thing you want to do is die?

It slips away from me as if covered in ice

Maybe it's a good thing that's what runs through my veins

Maybe I should focus on the familiar and have hope for change

My future has never been clear to me It seems as though every day I am faced with a new personality

Building new habits, looking at things differently Who am I to say who the future me will be? 
My future is ever-changing

As my tastes and interests expand and my

knowledge grows

I see who I am, what l've become, and what is still

unknown

The possibilities are infinite and that's what makes

it magic

The me that is here, today, will simply never know

My future is in the hands of a different me

I will not be who I am today

The memories that I currently have on replay will

be so insignificant

And will not take up space in my days

My future is in the hands of a better me

A much wiser, developed and intelligent me

A me that will understand that everything was

worth it

Though I may not show it on the surface

I will be so proud of me

My future will be

Whatever I want it to be 